\title{
More Severe Presentations of Acute Appendicitis During COVID-19
}

\author{
Cristian A. Angeramo ${ }^{1}$ (D) - Nicolas H. Dreifuss ${ }^{1}$ - Francisco Schlottmann ${ }^{1} \cdot$ Nicolas A. Rotholtz $^{1}$
}

Received: 6 November 2020 / Accepted: 24 November 2020 / Published online: 19 January 2021

(C) 2021 The Society for Surgery of the Alimentary Tract

Keywords COVID-19 · Acute appendicitis · Imaging findings · Computed tomography · Abdominal ultrasound

\section{Introduction}

Coronavirus disease (COVID-19) has caused unprecedented changes to almost every aspect of society. On March 11, 2020, the World Health Organization declared COVID-19 a pandemic. In order to contain the spread, Argentinian government rapidly declared a mandatory stay-at-home order on March 20th. ${ }^{1}$ We aimed to evaluate differences in imaging findings and postoperative outcomes of acute appendicitis (AA) patients between the COVID-19 pandemic period and a non-pandemic period.

\section{Methods}

We prospectively collected data of all patients who underwent laparoscopic appendectomy (LA) for AA between April 1, 2020, and August 31, 2020, during COVID-19 quarantine (G1) and compared them to a control group of patients who underwent LA during the same period in 2018 and 2019 (G2). Abdominal ultrasound (US) and computed tomography (CT) findings were reviewed and classified according to a modified score based on a reported classification: 1 normal, 2 nondiagnostic study, 3 uncomplicated AA, and 4 complicated AA. ${ }^{2}$ Complicated appendicitis was defined intraoperatively as a gangrenous or perforated appendix and severe peritonitis as the presence of fecal peritonitis in any quadrant or purulent fluid in more than one quadrant. The Kruskal-Wallis test was used to compare continuous variables, whereas the $\chi^{2}$ test was used for categorical variables. A $p$ value $<0.05$ was considered statistically significant.

Cristian A. Angeramo

angeramoagustin@gmail.com

1 Department of Surgery, Hospital Aleman of Buenos Aires, 1640 Pueyrredon Ave, Capital Federal, Buenos Aires, Argentina

\section{Results}

A total of 202 LA were included for the analysis: 60 during COVID-19 quarantine (G1) and 142 in the control group (G2). Clinical diagnosis of AA was supported by US in all cases, and the number of $\mathrm{CT}$ scans performed for AA diagnosis (G1: $30 \%$ vs. G2: $35 \%, p=0.43$ ) remained similar in both groups. US grade 4 AA (G1: $13 \%$ vs. G2: $4 \%, p=0.02$ ), periappendiceal fluid presence (G1: $63 \%$ vs. G2: $37 \%, p=$ 0.0005 ), and wider appendix diameter in US (G1: $11 \mathrm{~mm}$ vs. $\mathrm{G} 2: 9 \mathrm{~mm}, p=0.002$ ) were more frequent in $\mathrm{G} 1$. CT grade 4 AA (G1: $67 \%$ vs. G2: $23 \%, p=0.03$ ) and higher appendix diameter in CT (G1: $14 \mathrm{~mm}$ vs G2: $11 \mathrm{~mm}, p=0.008$ ) were also found in G1 (Fig. 1). Significant delays in consultation (G1: 54 vs. G2: 34 h, $p=0.0008$ ), higher rates of severe peritonitis (G1: $42 \%$ vs. G2: 15\%, $p<0.0001$ ), and more complicated appendicitis (G1: $38 \%$ vs. G2: $19 \%, p=0.004)$ were noted in G1. Patients in G1 also had higher rates of postoperative intraabdominal abscess (G1: $17 \%$ vs. G2: 7\% $p=0.04$ ), readmissions (G1: $12 \%$ vs. $\mathrm{G} 2: 4 \%, p=0.03$ ), reoperations (G1: $5 \%$ vs. G2: $1 \%, p<0.0001$ ), and longer total LOS (G1: 3 vs. G2: 2 days, $p=0.04$ ) (Table 1 ).

\section{Discussion}

Our study found that the use of abdominal ultrasound and CT scan for the diagnosis remained similar during the COVID-19 pandemic. However, we indeed found higher rates of complicated appendicitis by both imaging modalities. Contrary to our results, previous reports have shown a significant decrease in the overall number of radiological examinations for AA. ${ }^{3}$ An increased proportion of severe cases identified by CT scan have been also reported during the pandemic. ${ }^{3}$

Our findings could be partially explained by significant delays in consultation due to the "stay-at-home" order during the quarantine. ${ }^{4}$ Higher rates of complicated 
Fig. 1 Uncomplicated (grade 3) and complicated (grade 4) acute appendicitis by US and CT

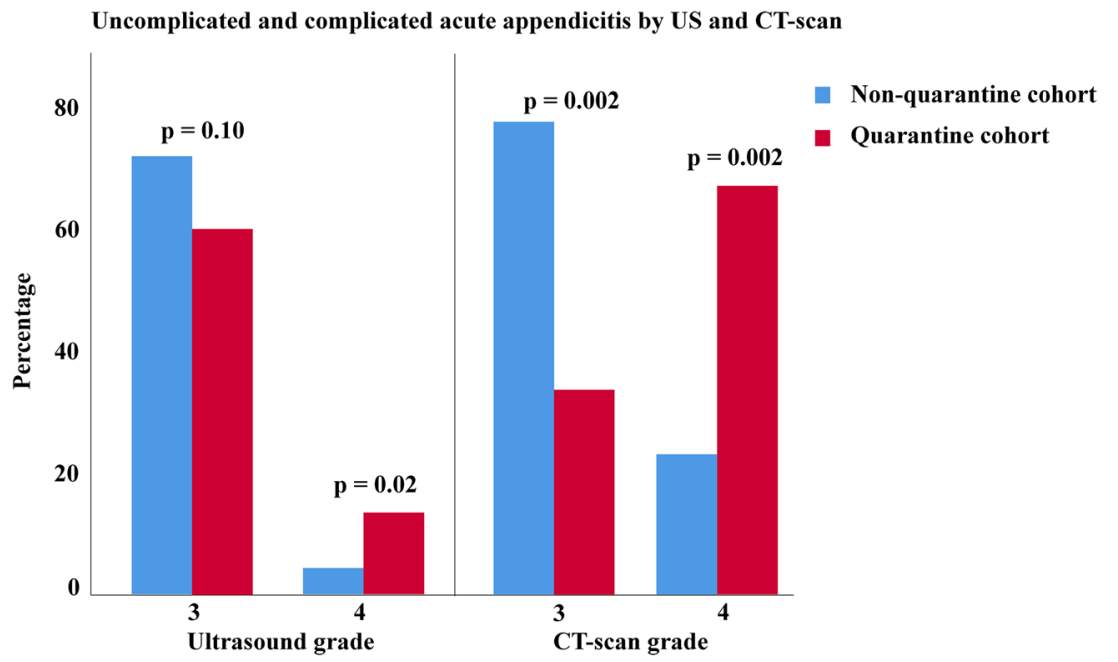

appendicitis and severe peritonitis were also detected intraoperatively, along with greater postoperative morbidity. Some authors have advocated for a shift in the management of AA during the pandemic towards the use of medical treatment with antibiotics. ${ }^{5}$ Although this treatment strategy seems reasonable in uncomplicated AA, it is likely to fail in patients with complicated appendicitis and/or peritonitis. ${ }^{6}$
Table 1 Perioperative variables and outcomes after laparoscopic appendectomy

\begin{tabular}{|c|c|c|c|}
\hline Variable & $\begin{array}{l}\text { G1 (COVID-19 quarantine) } \\
n=60\end{array}$ & $\begin{array}{l}\text { G2 (control group) } \\
n=142\end{array}$ & $p$ \\
\hline \multicolumn{4}{|l|}{$\operatorname{Sex}(n(\%))$} \\
\hline Male & $30(50)$ & $75(53)$ & \multirow[t]{2}{*}{0.71} \\
\hline Female & $30(50)$ & $67(47)$ & \\
\hline Mean age (range) (years) & $37(16-80)$ & $39(16-85)$ & 0.70 \\
\hline \multicolumn{4}{|l|}{$\operatorname{ASA}(n(\%))$} \\
\hline $\mathrm{I}-\mathrm{II}$ & $137(96)$ & $60(100)$ & \multirow[t]{2}{*}{0.14} \\
\hline III-IV & $5(4)$ & $0(0)$ & \\
\hline Previous abdominal surgery $(n(\%))$ & $17(28)$ & $28(20)$ & 0.18 \\
\hline Arterial hypertension $(n(\%))$ & $4(7)$ & $12(8)$ & 0.67 \\
\hline Diabetes $(n(\%))$ & $3(5)$ & $3(2)$ & 0.27 \\
\hline Mean white blood cell count (/mm3) & $13,264(6000-24,000)$ & $13,223(4500-25,000)$ & 0.90 \\
\hline Mean time to consultation (range) (hours) & $54(12-240)$ & $34(5-120)$ & 0.0008 \\
\hline Ultrasound AA grade $(n(\%))$ & $60(100)$ & $142(100)$ & 1 \\
\hline 1 & $1(2)$ & $3(2)$ & 0.84 \\
\hline 2 & $15(25)$ & $31(22)$ & 0.62 \\
\hline 3 & $36(60)$ & $102(72)$ & 0.10 \\
\hline 4 & $8(13)$ & $6(4)$ & 0.02 \\
\hline Diameter by ultrasound (mm (range)) & $11(18)$ & $9(6)$ & 0.002 \\
\hline Periappendiceal fluid $(n(\%))$ & $38(63 \%)$ & $53(37 \%)$ & 0.0005 \\
\hline Computed tomography AA grade $(n(\%))$ & $18(30)$ & $35(25)$ & 0.57 \\
\hline $1-2$ & $0(0)$ & $0(0)$ & 1 \\
\hline 3 & $6(33)$ & $27(77)$ & 0.002 \\
\hline 4 & $12(67)$ & $8(23)$ & 0.002 \\
\hline $\begin{array}{l}\text { Diameter by computed tomography } \\
\quad(\mathrm{mm} \text { (range) })\end{array}$ & $14(23)$ & $11(8)$ & 0.008 \\
\hline Complicated appendicitis $(n(\%))$ & $23(38)$ & $27(19)$ & 0.03 \\
\hline Severe peritonitis $(n(\%))$ & $25(42)$ & $21(15)$ & 0.01 \\
\hline Mean operative time (range) (minutes) & $52(20-120)$ & $49(15-105)$ & 0.87 \\
\hline Conversion rate $(n(\%))$ & $1(2)$ & $1(0.70)$ & 0.53 \\
\hline Mean LOS (range) (days) & $2.42(1-17)$ & $1.96(1-30)$ & 0.16 \\
\hline LOS with readmissions & $3(1-17)$ & $2(1-30)$ & 0.04 \\
\hline Readmissions $(n(\%))$ & $7(12)$ & $5(4)$ & 0.03 \\
\hline Intra- abdominal abscess $(n(\%))$ & $10(17)$ & $10(7)$ & 0.04 \\
\hline Reoperations, $(n(\%))$ & $3(5)$ & $2(1)$ & $<0.0001$ \\
\hline
\end{tabular}

$\mathrm{p}<0.05$ are denoted in italic

Abbreviations: ASA American Society of Anesthesiologists, $A A$ acute appendicitis, LOS length of stay 


\section{Conclusion}

We objectively demonstrated through imaging and intraoperative findings that patients with AA during COVID-19 pandemic have a more severe disease at presentation. Further studies are needed to determine potential detrimental effects of quarantine and "stay home" policies during a pandemic.

\section{Compliance with Ethical Standards}

Conflict of Interest The authors declare that they have no conflict of interest.

\section{References}

1. Cucinotta D, Vanelli M. WHO Declares COVID-19 a Pandemic. Acta Biomed 2020; 91: 157- 160.

2. Raptopoulos V, Katsou G, Rosen MP, Siewert B, Goldberg SN, Kruskal JB. Acute appendicitis: effect of increased use of CT on selecting patients earlier. Radiology. 2003;226(2):521-526.
3. Romero J, Valencia S, Guerrero A. Acute Appendicitis During Coronavirus Disease 2019 (COVID-19): Changes in Clinical Presentation and CT Findings. J Am Coll Radiol 2020;17(8): 1011-1013.

4. Dreifuss NH, Schlottmann F, Sadava EE, Rotholtz NA. Acute appendicitis does not quarantine: surgical outcomes of laparoscopic appendectomy in COVID-19 times. Br J Surg 2020; doi:https://doi. org/10.1002/bjs.11806

5. Javanmard-Emamghissi H, Boyd-Carson H, Hollyman M, Doleman B, Adiamah A, Lund JN, Clifford R, Dickerson L, Richards S, Pearce L, Cornish J, Hare S, Lockwood S, Moug SJ, Tierney GM; COVID: HAREM (Had Appendicitis, Resolved/Recurred Emergency Morbidity/Mortality) Collaborators Group. The management of adult appendicitis during the COVID-19 pandemic: an interim analysis of a UK cohort study. Tech Coloproctol. 2020; 1-11. doi: https://doi.org/10.1007/s10151-020-02297-4

6. Salminen P, Tuominen R, Paajanen H, Rautio T, Nordström P, Aarnio M, Rantanen T, Hurme S, Mecklin JP, Sand J, Virtanen J, Jartti A, Grönroos JM. Five-Year Follow-up of Antibiotic Therapy for Uncomplicated Acute Appendicitis in the APPAC Randomized Clinical Trial. JAMA. 2018; 25; 320(12):1259-1265.

Publisher's Note Springer Nature remains neutral with regard to jurisdictional claims in published maps and institutional affiliations. 